\title{
Permission to Rebel: A Critical Evaluation of Alcohol Consumption and Party Tourism
}

\section{Sheena Carlisle ${ }^{1}$ (D) Caroline Ritchie $^{1}$}

Received: 22 August 2019 / Accepted: 11 June 2020 /Published online: 2 July 2020

(C) The Author(s) 2020

\begin{abstract}
There is increasing societal worry about the long and short-term medical implications of binge drinking. There is also societal and fiscal concern about the impact that the rowdy carnivalesque behaviours engendered by the heavy drinking expected during a party tourism holiday has upon both the tourist and the local community. Therefore, a multi-disciplinary analysis of extant literature relating to the party tourism phenomenon and the consumption of excess alcohol which identifies gaps in current knowledge is timely. Reviewed from a British tourist perspective, the party tourism enclave primarily hosts friendship and rites of passage groups, and stag and hen parties where a high alcohol consumption is an expected, if not compulsory, holiday behaviour. The authors go beyond sole recognition of excessive alcohol consumption in beach destinations using thematic analysis to assess the role of the communal enclave space, the power of place and representations of drinking to excess via media and holiday discourses. This is measured in the context of culturally (un)acceptable behaviours within different drinking groups according to demographics, peer group pressures, purpose of holiday and personal incentive to drink. This links to roles of social media, levels of risk tourists are willing to take, memories of holiday drinking experiences, the role the hospitality and tourism industry in promoting alcohol consumption and levels of governance and policing within the party tourism destination. Recommendations are made for future empirical research to inform policy and practice within party and nightlife destinations.
\end{abstract}

Keywords Party tourism · Beach enclaves · Alcohol consumption · British tourists · Young adults $\cdot$ Liminal experiences

Sheena Carlisle

scarlisle@ cardiffmet.ac.uk

1 Cardiff Metropolitan University, Cardiff, Wales, UK 


\section{Introduction}

This study considers in detail the role of alcohol and the party tourism context from a British perspective for two reasons. First, as the United Nations World Tourism Organization (UNWTO) (2016) notes, in 2015 the United Kingdom (UK) was the fourth largest source market for international tourism and led demand in Europe. Mintel (2016) showed that one in three British tourists went to Spain and particularly popular destinations continue to be the islands of Majorca and Ibiza which contain the renowned party tourism hotspots of Magaluf and San Antonio respectively. Second, (discussed in detail later) while concern about alcohol related harm to society is worldwide (Nicholls 2016) there is growing concern in the UK about an alcohol consumption paradox. The concern is that although overall alcohol consumption is falling in the UK, particularly amongst younger adults (Euromonitor 2016; Official National Statistics (ONS) 2015; Snowdon 2015), the prevalence of binge drinking, again amongst younger adults, will ultimately lead to a rise in alcohol related harms (Bellis et al. 2015) as well as more local social and cultural harms.

The theoretical context for this paper is a merging of the authors' separate interests in social drinking behaviours and socio-economic issues and impacts arising in destinations via tourism development, see Ritchie et al. (2009); Velikova et al. (2016); Carlisle and Jones (2012) and Carlisle et al. (2016). Reflecting Fishbein and Ajzen's (1975) theory of reasoned action which posits that peoples' behavioural intentions are functions of two basic determinants; attitude towards a particular behaviour and subjective norms, plus their own research expertise, the authors analysed current literature relating to the phenomenon of party tourism in the context of alcohol use. However, they extended their review to also consider societal impacts arising from those determinants. In this paper, and discussed in detail in the next sections, the term party tourism identifies with Bell's (2008) work on alcotourism focussing upon those who travel with the specific intention of drinking excessive amounts of alcohol and indulging in associated risk-taking adventures.

The themes discussed in this paper arose from this critical analysis namely gender, the embodiment of space and liminality, the influence of media, industry attitudes and government policy. These themes provide a multi-dimensional perspective of excessive drinking behaviour whilst on holiday. Thematic analysis was therefore employed to provide the foundational method for qualitative analysis and provide a means of interpreting data and text (Braun and Clarke 2006), in this case journal articles and book chapters, plus significant representation in the media, in a rigorous and conscientious manner. This allowed searching for emerging and underlying themes involving careful reading and re-reading of the data (Fereday and Muir-Cochrane 2006).

Through this critical analysis, gaps in current knowledge are identified and illustrated in Fig. 1, Alcohol Related Research Gaps in Party Tourism. The model identifies areas, which would benefit from future empirical research to assess the motivations, impacts and implications arising from party tourism. Identifying and addressing these gaps will help to inform policy direction and strategy for host destinations of party tourism in alleviating the negative impacts of party tourism and recognizing fewer damaging ways of celebration. Included in developing a better understanding of the party tourism phenomenon is developing a better understanding of the role of, and tension between, national and local government in the regulation and licencing of 


\begin{tabular}{|c|c|c|c|c|c|}
\hline & \multirow[t]{2}{*}{ Positive } & $\begin{array}{l}\text { Holiday } \\
\text { relaxation }\end{array}$ & \multirow[t]{2}{*}{$\begin{array}{l}\text { Seasonal income } \\
\text { and employment }\end{array}$} & \multirow[t]{2}{*}{ Positive } & \\
\hline \multirow{6}{*}{ 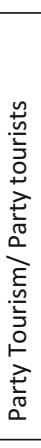 } & & Emotional release & & & \\
\hline & \multirow{5}{*}{ Unknown } & $\begin{array}{l}\text { Permission to } \\
\text { rebel }\end{array}$ & $\begin{array}{l}\text { Internationalisation } \\
\text { of local culture }\end{array}$ & \multirow[t]{5}{*}{ Unknown } & \multirow{5}{*}{ 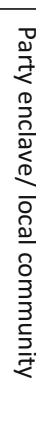 } \\
\hline & & $\begin{array}{l}\text { Long term alcohol } \\
\text { related harms }\end{array}$ & \multirow{2}{*}{$\begin{array}{l}\text { Economic benefit - } \\
\text { low skilled seasonal } \\
\text { employment or } \\
\text { high quality } \\
\text { permanent } \\
\text { employment } \\
\end{array}$} & & \\
\hline & & $\begin{array}{l}\text { Social damage via } \\
\text { images on social } \\
\text { media }\end{array}$ & & & \\
\hline & & $\begin{array}{l}\text { Pressured to } \\
\text { rebel }\end{array}$ & Social cohesion & & \\
\hline & & Role of voyeurism & $\begin{array}{l}\text { Voyeuristic cultural } \\
\text { acquisition }\end{array}$ & & \\
\hline & \multirow[t]{2}{*}{ Negative } & \multirow{2}{*}{$\begin{array}{l}\text { Immediate } \\
\text { alcohol related } \\
\text { harms }\end{array}$} & $\begin{array}{l}\text { Out of season } \\
\text { unemployment }\end{array}$ & \multirow[t]{2}{*}{ Negative } & \\
\hline & & & $\begin{array}{l}\text { Environmental } \\
\text { damage }\end{array}$ & & \\
\hline
\end{tabular}

Fig. 1 Current assumptions in research of party tourism

premises from both policy and enforcement perspectives. Similarly, a better understanding is also required of the voyeuristic role of the media, which equally opposes and advocates transgressive behaviours to a mass audience blurring what is unacceptable at home and acceptable abroad.

\section{Identifying Party Tourism as a Subset of Mass Tourism Holidaying}

A holiday is a period of time when the normal cares of daily life are removed, and any activity undertaken is generally undertaken for the pleasure it will bring the consumer of that activity. In Andrews' (2011) seminal work on the behaviours and attitudes of the British on holiday, this permission to relax is particularly reaffirmed in the mass tourism market by the package holiday. This she identifies as an opportunity to relinquish normal routine responsibilities allowing a reversion to childlike behaviours and irresponsibility. This relinquishing of normal responsibilities, proactively supported by tour operator packages, takes over the hard work of holiday organization and is particularly prevalent in the party tourism context.

According to Vanhove (1997) mass tourism definitions primarily represent two quantitative characteristics; participation of large numbers of tourists in a single tourism location and a rigid standardization of the holiday package. Vanhove (1997) cites Fink (1970) who highlights the conscious integration of the tourist with the travelling group, large numbers and collective accommodation settings as key factors supporting the categorisation of mass tourism. More recently, Cárdenas-Garcia and Sánchez-Rivero (2015) identified access to the coast, good transport access and good internet connections as three further significant pull factors in supporting the development of mass tourism. For many northern Europeans, including Britons, warmth and a sunny climate are major holiday draws and for alcotourists (Bell 2008) access to alcohol is essential. Therefore, the mass tourism enclave concept applied here represents sunny coastal destinations, easy transport infrastructure, purpose-built accommodation facilities, a 
good image and presence via media and tour operators. In the case of party tourism (Bell 2008), this also includes invitations to participate in group-drinking activities such as pub and bar crawls, boat parties and nightclubbing. Examples of party enclaves popular with British party tourists include Magaluf in Majorca, Haad Rin Beach on Ko Phan Nyang, Thailand, Cancun, Mexico, Kavos in Corfu, Faliriki in Rhodes, Malia and Ayia Napa in Crete and Sunny Beach in Bulgaria. These destinations represent a diverse geographical set of locations, but all have the associated infrastructure, which supports the facilities and services required by party tourists.

The authors accept that some young adults visiting party tourism enclaves such as San Antonio in Ibizia, will go for the music and dance scene, not with the intention to consume excessive amounts of alcohol. They also accept that many party tourists often, but not always (Tutenges 2012) intend to increase their drug usage and or seek out casual sex (Thompson 2017). For yet others the anticipation of observing rather than participating in these behaviours may be the significant draw (Redmon 2003). However, easy availability and consumption of alcohol is an expected facility within all party tourism destinations whether or not the party tourists' prime objective is to drink to excess (Thurnell-Read 2011).

\section{Identifying Party Tourism as a Subset of Alcotourism}

As Moore and Measham (2012) point out most people who drink alcohol do so because of the pleasure it brings them; while most consume moderately most of the time, for some being drunk is a deliberate and positive outcome of drinking alcohol. This particularly occurs in times of leisure or celebration such as a holiday. Bell (2008) identified many forms of what he calls alcotourism where consumers seek to combine the sense of place of a tourism destination with the culture of that place, via the alcohol produced and or its drinking cultures. This may take the form of visiting an Irish themed pub to feel the 'craic' outside Ireland or visiting a champagne house in France to better understand how this luxurious beverage is made. These activities form part of the growing experience economy (Pikkemaat et al. 2009; Pine and Gilmore 2011) with new experiences proactively sought as a key facet of the liminal, time constrained holiday.

However, alcotourism, as Bell (2008), Hall et al. (2000) or Cogan and Charters (2014) show, does not habitually mean participating in a period of disruptive alcohol consumption and transgressive behaviour which challenges the customs and norms of the local environment. Indeed activities such as wine tourism are normally seen as a positive form of niche tourism in which the tourist not only seeks to participate in the local food and drink offerings and traditions but also in activities which are both financially and environmentally supportive of the local economy (Cogan and Charters 2014; Hall et al. 2000; Ferraz Ribeiro and Moreira 2015). By complying with local rules of drinking consumption and comportment, the tourists seek to understand the culture of the destination rather than ignore or abuse it. Bell (2008) sees these niche tourism activities as an outward seeking form of alcotourism, which links to gastrotourism, cultural heritage and sustainable tourism development. Such activities embedded into the dramaturgical performance of space include the role of the landscape and cultural environment, acceptable tourism activities and experiences 
and development of facilities and infrastructure to support this. Baerenholdt et al. (2004) recognized the role of the vineyard, winery and restaurant to support wine tourism.

In stark contrast to wine tourism, party tourism has evolved around the concept of 'the Strip' with nightclubs and bars in situ to support a party carnivalesque atmosphere. This can be described at the opposite end of an alcotourism spectrum and a form of mass tourism in which the 3rd S is replaced with an A: sun, sea and sand giving way to sun, sea and alcohol. This type of alcotourism matches the earlier definition of enclave tourism in that it is usually an inclusive package aimed, although not exclusively, at the 18-30 age group (see tour operator websites Thompson or On the Beach (2017)). The geography of a party tourism enclave is not always within a physically gated community, i.e. Sunny Beach in Bulgaria. However, it is almost always based on a 'drinking strip' i.e. San Antonio in Ibiza (Briggs 2013), Kavos in Corfu (Williams-Burnett et al. 2017) or a cluster of drinking venues around several streets, such as Magaluf in Majorca; these strips form the mental boundaries of the enclave.

Providing its own dramaturgical space, within the strip are crowded together the many features of the night time leisure experience which the participants are familiar with at home, e.g. bars, clubs, fast food outlets (Aresi and Pedersen 2016; Briggs 2012; Fjær and Tutenges 2017; Hughes et al. 2011) but in a warm outdoor climate. Additionally, Carr (2002) points out that there is often a significant replication of home in evening leisure activities sought by young people in a holiday environment, i.e. going out in friendship groups. The main difference may be the intention of drinking more alcohol than they would on a similar single night out at home. This has two potential consequences: first, most party packages cover a period of several days during which time many participants will drink alcohol from early in the morning until late at night while simultaneously significantly reducing the amount of sleep, or down time, they get actually making themselves ill (Fjær and Tutenges 2017; Thurnell-Read 2011). Second, it reflects what Mawby (2012), Thurnell-Read (2012), Tsartas, Papatheodorou and Vasileiou, (2014) and Aresi and Pedersen's (2016) work shows as the introverted, often inward looking integration of people which frequently occurs within mass tourism enclaves; an internalizing exclusivity which can lead to a lack of respect for local norms, culture and environment. This is enhanced when the transgressive behaviours (rowdiness, noise, etc.) associated with excess alcohol consumption are introduced into the holiday package. In addition, the package is usually purchased with a large international tour company and may be fully inclusive; meaning that very little money is actually spent within the local economy (Williams-Burnett et al. 2017).

The UK target markets for party tourism include stag, hen and divorce parties, rite of passage or leaving school group parties and gap year travel organized by tour operators for example: clubbing holidays, previously known as 18-30 holidays, offered by TUI and Loveholidays.com, PartyHard.com. The promotion and commercialisation of drinking via drinking tours, happy hours and all-inclusive drink offers, is part of the attraction actively advocating alternate risk seeking behaviours such as binge and excessive drinking behaviours within the party enclave environment. As following sections show participating in the party tourism performance and then recalling that participation via stories and media are further key elements of the party tourism package. 


\section{The Role of Performance, Place and Identity in the Enclave Space}

Room (2005) identified the nature of alcohol use as an ethnic marker, shaping the place according to the behaviours and attitudes displayed by fellow tourists. Thus, alcohol consumption can provide markers for comparative analysis where tourism may lead to alternative or similar behaviours abroad and at home (Andrews 2011). Lew and Cartier (2004) recognized how tourists shape places to reflect identities in as much as places influence opportunities to affect the wellbeing of tourists. This can be in either a positive or a negative sense where potential for hazards, accidents and ill health increases in foreign environments that tourists are unfamiliar with. This fine balance between the provision of fun, escapism and safety correlates with the concept of the 'embodiment of space' in enclaves which house buildings dedicated to enabling tourists to use their individual personalities to practise and perform (Crouch et al. 2001; Edensor 2001). This landscape of power in beach enclaves represented via the respective hotels, bars and clubs becomes a key influence in relations between stakeholders (Carlisle and Jones 2012) and relates to the tourist embodiment of space and their interaction with such businesses. This challenges the level of responsibility which enclave based companies and the local authority are willing to take whilst also encouraging tourists to drink excessively. This confronts their role and influences how a tourist embodies space. This relates to the work of Eliade (1968:37) cited in Wearing, Stevenson and Young (2010:37) who linked the concept of leisure to escaping familiarity and attempting 'to escape the tyranny of time through a bewildering number of distractions'; thus home life represents stress, sameness and blandness and the holiday location as a space to relax and unwind .

Hughes et al. (2011) and Briggs's (2013) studies show that drinking behaviours and attitudes at home influence the type of drinking behaviours evidenced in party tourism spaces abroad reflecting perspectives of place and identity. Paradoxically, and reflecting Carr's (2002) study, Edensor and Falconer (cited in Wilson 2012) identified how holidays also represent the search for the familiar and routine in the enclave context, i.e. replication of home leisure facilities such as bars and clubs.

The above circumstances of an enclave holiday support Rojek (2000):149) that 'by allowing and encouraging the individual to stand outside the ordinary flow of collective values, axioms and conventions, leisure in liminal settings is potentially culturally transformative'. This occurs where enclave environments transform to suit tourist desires and expectations, allowing the exploitation of economic opportunities. This concept of transformation of a place demonstrates that the enclave space supports consumption and emotional release through the presence of large groups who gather in mass tourism settings, which represent togetherness and co-presence (Giddens 1987 in Baerenholdt et al. 2004). The ability of mass tourism to offer this collective experience includes relinquishing responsibility for organization and control to the tour operator and hotel; adding an extra dimension to the attractiveness and irresponsibility of party tourism. In addition, the liminal structures and qualities of holidays that support a loosening of inhibitions and an attraction to the forbidden and out of reach (Rojek 2005) arguably support the wild and mephitic behaviours apparent in the binge drinking behaviours identified in party tourism.

Baerenholdt et al. (2004) refer to Lefebvre's 1991 seminal work on the production of space, likening, for example, the beach to a stage that provides a space of a dream 
where it has full play of all desires and a dramaturgical space for performing tourism (Chaney 1993). They suggest that it is an extension of space that permits freedom and lack of regulation enabling opportunities of performance and a ludic quality of tourism which is different from everyday life. This contrasts to the opposite view of enclaves as cleverly managed, regulated and controlled spaces with playwrights, directors and stage crew (Edensor 2001) who support the supposedly rebellious spaces the tourists have come to enjoy, a perspective confirmed by Turi (2017) in relation to party tourism. In Larsen's (2012) work on performance in tourism spaces the link between emotional geographies of tourism and the importance of being with family and friends who can perform together, relates to the enclave context of mass tourism and drinking alcohol where spaces of enforced intimacy (the strip) are chosen to support the perception of enhanced social drinking permissions. Thurnell-Read (2011) and Larsen (2012) support the view that most party tourism participants are not passive readers of the discourse of the party tourism offer, rather they are actively engaged by the potential to perform party tourism.

Whilst the above discussion presents some commonalities of the lure of enclaves in general, Craik's (1997:118) view that 'all tourism experiences occur in terms of prior knowledge, expectations, fantasies, and mythologies generated in the tourist's origin culture rather than by the cultural offerings of the destination' can be applied to the party tourism context. Wearing et al. (2010) support this view, suggesting that searches for recreation and tourism are associated with family, tribe and class: the principles, cultures and social rules displayed on holiday are based upon these groupings back home. In this sense, party enclaves can provide a familiar social and communal space for both expression and role reinforcement as well as an opportunity to play with role identities. As Andrews (2011) suggested, the role of package holidays is to seek play and transcendence from normality within a familiar context; as previously noted, party enclaves contain many of the features of the home night time leisure environment (Aresi and Pedersen 2016; Briggs 2013; Fjær and Tutenges 2017; Hughes et al. 2011) but within an alternate physical and liminal space.

Rojek (2005:183) applied Foucault's view that people are not always bounded by institutional powers, codes and legislations, and that it is natural for human beings to seek a 'limit experience' that rejects discursive limits to identity and practice and allows a search for new forms in a de-regulated space, such as a party enclave. This can be associated with the concept of edgework, first conceived by Lyng (1990, 2005) who investigated the link between leisure and risk-taking activities and putting oneself to the edge of one's limits. Party tourists are not contained and bound by the normal codes and laws for drinking, instead they receive permission (encouragement) from bars, tour representatives (tour reps) and their peers to drink excessively (Kelly et al. 2014; Thurnell-Read 2011; Williams-Burnett et al. 2017). Party tourism spaces usually strongly and proactively support the relaxation of rules and the rejection of normal modes of practice leading to abnormal practice (Rojek 2005) which, in the case of party tourism, may include displays of nudity or lewd public displays of behaviour. This explains one of the attractions of party tourism; to test and challenge moral boundaries by operating on the edge of legal and discursive boundaries which weaken standard modes of discipline.

This ability of leisure to support self-actualisation and self-realization (Lyng 1990) places the enclave resort as a key socio-geographical structure enabling the motivation 
and context for pursuing party tourism. Thus, party tourism reflects three main types of 'abnormal leisure' (Rojek 2005) used extensively in sociological analysis. These include wild, mephitic and liminal structures that can be adopted to help support an understanding of the popularity of the phenomenon of excessive drinking in party tourism spaces and the acting out of vicarious fantasies and pleasures. However, and reflecting Redmon's (2003) observations of vicarious fantasies and pleasures at Mardi Gras, it is likely that these would not be considered abnormal in the party tourism context. Wild leisure focuses on carnivalesque atmospheres and allows sporadic opportunities to escape social scripts which are perceived as limiting and may lead to transgressive behaviours (Purves et al. 2014; Rojek 2005). Katz (1988) explained how observing drinking behaviours could be exciting which links to the voyeurism which may be observed in classic tourist behaviour and was evident in the Sunny Beach season (Turi 2017). Mephitic leisure creates more dangerous and violent behaviours, which may be linked to aggression as a result of drinking excessively, such as 'balconing' (Piggot 2016) or participating in fights.

In their study of risk-taking tourism, Uriely and Belhassen (2005) discuss the concept of controlled decontrol. They raise the question of whether transgressive and risky tourist behaviours, such as drug taking, are a reaction to living in a society where expectations of refined, civilized behaviours are continually increasing. The deliberate decision to participate in transgressive, risky behaviours is knowingly undertaken, although in many instances, as Tutenges (2012) notes, control over decontrolled behaviours remains a constant presence in the mind of the tourist; the management of and by the party enclave stakeholders permits participation in decontrol. Thus, part of the attraction of party tourism is pushing at the boundaries of acceptable home consumption behaviour.

\section{Drinking Habits in the UK}

As previously stated, overall alcohol consumption is falling in the UK and has been for over 10 years (Euromonitor 2016; Snowdon 2015;). This fall in overall alcohol consumption is being driven by those in the younger adult age groups (ONS 2015). However a small number of recent studies in this area (e.g. Burton et al. 2016; Holmes et al. 2016) are beginning to suggest that intensely concentrated alcohol consumption during the holiday period causes much more medical harm than an overall higher but more moderate annual consumption. This potential harm may occur even though the holiday binge only lasts for a week or two once a year.

According to a Public Health England report (Burton et al. 2016) binge drinking (which is defined as drinking more than eight units of alcohol in 1 day for men and six for women) is highest in the younger adult age groups and peaks in the 25 to 34 group (party tourism's target market). Holmes et al. (2016) found that those over 35 and from higher socio-economic groups drank the most alcohol overall. However, their findings agreed with those of Burton et al. (2016) in that those from the younger age group were much more likely to binge drink. Additionally, it was the very abusive binge drinking, not the total alcohol consumed over time, which was likely to be the cause of more alcohol related issues (violence, hospital admissions, etc.) occurring in younger adults. By investigating the consumption of alcohol during atypical as well as typical time 
periods Bellis et al. (2015) could show a rise of over $18 \%$ of recalled alcohol consumption which related almost entirely to heavy drinking episodes such as celebrations and holidays. These findings supported the earlier finding of Hughes et al. (2011) study which suggested that if the young party tourist goes out each night of their holiday, as is the norm, then they may compress one fifth of their annual number of nights out, and accompanying alcohol consumption, into that two-week period. These studies all suggest that very significant amounts of alcohol are habitually consumed by young adults during relatively short concentrated periods of time and that heavy periodic binge drinking such as during celebrations and holidays, especially party holidays, greatly increases potential consequences for both immediate violence and physical injury as well as long term health issues.

Hen (female) and stag (male) parties are a UK tradition in which a great deal of alcohol is drunk as a final symbolic farewell acknowledgement towards the single lifestyle on the eve of a wedding and commitment towards a more moderate, sharing future. While these used to be a single night of excess it is now very common for the hen or stag party to be a holiday package abroad (Andrews 2011; Bell 2008; ThurnellRead 2011). While the young single party tourists may be progressing through a rite of passage moving from family holidays to adulthood, the hen or stag party is characterized by an intention to 'maximize celebration' (Aresi and Pedersen 2016:211) or party to excess (Thurnell-Read 2011). Bell (2008) and Croft (2017) noted the dominance of young single sex friendship groups or hen and stag parties in the UK nighttime economy which is replicated in the target markets for party tourism.

In their study of Danish party tourists in the Sunny Beach enclave in Bulgaria Hesse et al. (2008) identified that most of those who were participating in the party tourism also reported behaviours which suggested that they were likely to be heavy, binge drinkers back home. This may suggest that the party tourism package predominantly attracts those already predisposed towards heavy drinking and the transgressive norms of this type of holiday.

\section{Gendered Perspectives of Party Tourism}

The role of gender is also a key factor of influence that indicates differing approaches and attitudes to drinking abroad. This is also influenced by cultural and social behaviours at home. Significantly, the role of pubs in UK culture has an important connection to party enclaves abroad. According to Storry and Childs (2017) there are 48,000 pubs in Britain representing a key part of British culture providing opportunities to socialize, meet friends and family and feel a sense of community. Although still dominated by male customer (Croft 2017) the main role of the pub is to provide drinking spaces which are generally seen as safe policed spaces for its consumption (Fox 2004). Extending beyond the pub is the ritual of clubbing where single sex friendship groups are as common as mixed sex groups; women frequently use the occasion to dress up glamorously to impress or gain approval from each other as opposed to attracting men (Bell 2008: Croft 2017). Briggs (2013) pointed out that most groups in his study of British tourists in Ibiza were single sex, friendship groups. This phenomenon is particularly reflected in hen and stag groups but is also reflective of clubbing norms in the UK. More negatively, Croft's (2017) study confirmed that whilst 
the traditional image of heavy drinking groups is young adult males, the rise of the ladette culture means that all female groups can show the same transgressive behaviours as all male groups in terms of noise, abuse and violence.

Ritchie et al.'s (2009) study analysed the binge drinking behaviour of young British adults; their work suggested that image may have as significant an impact upon the associated transgressive behaviours as the alcohol consumed. For example, they noted the need of young male adults to have 'war stories' to express what happened if the evening was to be considered a good night out but that noise, dance and general exuberance could contribute to anti-social behaviour as much as the alcohol itself. Like Carr (2002), Ritchie et al.'s (2009) work also identified the potential impact of work upon drinking to excess and related transgressive behaviours. They suggested that as young adults moved up the career ladder taking time off work because of a hangover or alcohol related injury became much less acceptable, being seen as unprofessional behaviour. This view is supported by Briggs (2013); since the holiday removes the need to go to work it may be that by removing the need to maintain a professional work image the young adult now has permission to revert to earlier transgressive behaviours which were acceptable when they had much less responsibility. Reflecting on the work of Hastings (2010), Thurnell-Read $(2011,2012)$ and Purves et al. (2014) young male adults in particular, may discover a need to replicate the carnivalesque rowdiness of their earlier drinking behaviours so that they can publicly demonstrate that they are having the good time expected of them on a party holiday.

However, although Ritchie et al. (2009) and Croft (2017) identified the rise of the ladette culture and of young adult women in the UK drinking like men, Thomas's (2005) study suggested female behaviour in the party tourism context may differ from that of their male counterparts. As the title of her study suggests; 'What happens in Tenerife stays in Tenerife'. Uriely and Belhassen (2005) also identified a similar female code of silence in relation to drug taking. The UK females that Thomas (2005) interviewed fell into two groups, those travelling in larger groups and those travelling in twos or threes. In the smaller groups, she identified much more pre-holiday intention to transgress and behave in ways that would be unacceptable for females in their home environment. This included not just getting drunk but also the intention of having casual sexual adventures. These women travelled with small groups of close friends who unlike their male counterparts could be trusted not to tell any stories when they returned home which might affect their public, moderate image. Those who travelled in the larger groups did not have these pre-party holiday intentions and believed that, as at home, the peer pressure of the group would ensure that their behaviour was acceptable to their social group and, therefore, so would any resulting stories or images. Ragsdale et al.'s (2006) study also showed a similar behavioural difference between groups of women holidaymakers in Costa Rica. This feminine control is supported by the work of Niland et al. (2014) who showed that, unlike their male counterparts who needed risk taking stories to demonstrate their masculinity and enjoyment, the female participants in their study worked hard to ensure that the only images pasted on Facebook after a party event were ones which complemented their public image. These behaviours are likely to be replicated in the behaviour of participants in party tourism. 


\section{Permissions and Affirmation through Media}

As previously mentioned, the media plays a significant role in promoting the image and bravado of excessive alcohol consumption as a norm. Wearing, Stevenson and Young (2010: 80) explain that the holiday and leisure environment, provides a 'world of commodified images and experiences which can overpower, disorientate and hypnotise the tourist...the colourful display of neon lights, bars and nightclubs are appropriate to the need for stimulation of over excited and exhausted nerves'. The image and lure of the party enclave space generates expectations of the party enclave as a destination where drinking excessively and transgressive behaviour is expected if not essential and later to be publicly displayed on smartphones, via social media (Tutenges and Sandberg 2013) and possibly in newspaper articles and television programmes. Indeed, as Williams-Burnett et al. (2017) confirm television programmes such as Sun, Sex and Suspicious Parents, A and E Abroad and What Happens in Sunny Beach and Kavos, all reaffirm the popular drunk image of the party tourist abroad.

Cable and Sacker (2007) and Smith and Foxcroft (2007) have shown that adult interaction with alcohol is related to expectations of alcohol related behaviours learned in adolescence. Building on this concept Gunter et al. (2008) suggested that whilst alcohol advertising might not actually promote the onset of underage drinking it certainly started young people thinking about it and aspiring to participate in 'cool' scenes/ activities in which they saw alcohol consumed. However, Lobstein et al. (2016) study suggests that there is evidence from the USA that the movement towards digital marketing may have changed this as young people especially feel the need to create socially acceptable images of themselves on social networking sites (Niland et al. 2014). Purves et al. (2014) demonstrate that liking particular brands of alcohol and or images of excessive alcohol consumption is a way for current British teenagers to create a public image that they believe will help them to make friends and extend their social circle. That is, beliefs which may or may not be actively supported by the brand owners themselves (Nicholls 2016). Thus, although it is illegal in the UK to deliberately market alcohol to young adults (under 18), as Hastings (2010), Purves et al. (2014) and Lobstein et al. (2016) point out, through deliberate terrestrial marketing, television and social media, young people are normalized to aspire to engage in fun, social situations where they see alcohol being consumed in often unpoliced hedonic environments.

Lim (2014) suggests that the concept of customer hedonism is significant to the experience economy not only during the hospitality experience purchased but also in the consumers' recall of it post-holiday and thus their re-purchase or loyalty intentions. Whilst Lim's (2014) study relates to the hospitality servicescape meeting the customers' hedonic expectation, Bosangit et al. (2015) suggest that this is also true of the entire holiday experiencescape. Not only must the customer enjoy the experience they have purchased but where the purchase is significant and or publicly displayed, they must be able to demonstrate via stories after the holiday that it met or exceeded expectations. This supports Best, Maktelow and Taylor (2014) and Ryan et al. (2017) studies which emphasize the positive aspects of social media which are used to raise levels of social capital, provide a sense of community amongst friends, a safe place for identity experimentation and increased opportunity for self-disclosure. 
The existential authenticity (Wang 1999) of the party tourism experience habitually contains a carnivaliesque element where the party tourist must be seen to be participating either by consuming alcohol and having fun or suffering from the effects of excess alcohol consumption (Thurnell-Read 2011). This reflects images often portrayed on British television documentaries such as Sun, Sex and Suspicious Parents (BBC3 2011-2015; cited by Williams-Burnett et al. 2017) and the headline stories of excessive drinking behaviours in British newspapers which are shocking, enticing and reaffirming all at the same time. Therefore, in the case of party tourism public demonstration means demonstrating the appropriate consumption of alcohol through verbal recall and appropriate imagery including social media such as Twitter, Instagram or WhatsApp.

However, using social media to publicly display behaviours abroad demonstrates a contradiction in the behaviour of many young adults in both needing to publicly demonstrate their participation in transgressive party tourism while also seeking anonymity and escapism in travelling abroad to search for hedonistic experiences (Fennel 2006; Redmon 2003). Redmon's study in 2003 analysed behaviours at Mardi Gras where visitors could openly perform transgressive behaviours yet have the intention of remaining unchallenged and anonymous. This contrasts with Tutenges and Sandberg's (2013) more recent study which showed that a decade later many holiday makers in fact want a social media presence to validate their holiday experience. Using photos, videos and discussion during their holiday of their holiday drinking stories they, themselves, publish them on social media sites during and after their return home to fit with the expectations of both the holiday and their social groups. However, since it is now expected that the holiday experience will be recreated and made public care needs to be taken to ensure that the transgressions do no more than push the boundaries of acceptable transgressive behaviour or where they were beyond these boundaries that they were enjoyed vicariously, observing the other. Thomas (2005) and Niland et al. (2014) show how this frequently means mediating, altering, the reality of the image they place in the public domain so as not to spoil their image back home.

This said, it is important to recognize that individuals vary in their need to belong and use of social media according to willingness to communicate, levels of social anxiety and rejection sensitivity (Ryan et al. 2017). Their study suggests that these individual difference characteristics may cause social media users to ascribe very different meanings to the same experience. For example, a person who has a strong need to belong, despises the idea of being alone and can be easily hurt when they are excluded from groups. The response of friendship groups to holiday behaviours and the number of 'likes' or comments on social media can be construed as a public display of the enjoyment a person brings to others through sharing of holiday experiences. It also reinforces the way they perceive and remember their holiday experiences; receiving a high volume of likes and positive comment may have an especially positive impact while failure to receive any feedback on posted content may lead to a sense of social exclusion or rejection and a more negative recall. Antunes et al. (2018) discuss the main factors which motivate tourists to express themselves through social networks and conform to societal norms whilst on holiday including: the ease of communicating, sharing and storing content; engaging with the opportunity to show off as the tourist enjoys the idea that their acquaintances want to do or know what he/she is doing; sharing experiences and stories that truly deserve to be told; inviting others to live the 
experience; sharing happy moments with friends and acquaintances; expressing sociability.

In the context of this paper social media represents an affirmation of experiencing, sharing and responding to drinking experiences during and after holidays. Party tourists, however, may not have full control over their image, as they may be unknowingly included in other's posts or, as Tutenges and Sandberg (2013) point out, they may find that transgressions of theirs which may exceed acceptable boundaries are recorded and published by others in their group who also enjoyed the experience, but vicariously. These characteristics provide a fluid platform from which party drinking experiences are shared.

\section{Tour Operator Roles in Supporting Party Tourism Excess}

There is an accepted perception that all who participate in party tourism want to indulge in transgressive behaviours. However, in contrast to this and reflecting Katz (1988) and Urieley and Belhassen's (2005) work on voyeurism and controlled decontrol, it is notable that in Stacey Dooley's BBC3 (2013) investigation into alcohol related behaviours the male stag group being observed was obviously uncomfortable with the compulsory and explicit strip tease arranged for the stag, as was the stag. The stag party was in fact noticeably much happier drinking and dancing in their all male friendship group. This observation agrees with the work of Thurnell-Read (2012) in suggesting that the image of excess behaviour, including the objectification of women, was perhaps more enjoyable in concept than in reality and in the observation of others behaving badly, usually at the encouragement of the tour reps. This concept is supported by most parents in the BBC Sun, Sex and Suspicious Parents television series which ran from 2011 to 2015, who were deeply relieved to observe that whilst their child may well have talked wildly prior to the holiday most did not participate in the most excessive behaviours. Indeed, Williams-Burnett et al. (2017) point out that much of the extreme behaviour is in fact staged for the film and TV companies rather than occurring organically.

Tutenges $(2012,2013)$ also notes this contradiction. The participants in his study did intend to behave in ways, which would be unacceptable back home, but within safety boundaries, they set themselves. Interestingly this included being worked up into an unrestrained state of exuberance by the tour reps. Where this liminal state was not achieved the party tourists complained. Tutenges (2013) and the earlier work of Pritchard and Morgan (1996) show that the tour rep is key to the development of the festive carnivalesque atmosphere being sought. As Kelly et al. (2014) study shows many tour reps were originally party tourists themselves who return to the party enclave to enjoy the hedonistic experiences they enjoyed as a tourist but for payment. They are employed by the tour operators to make sure that the wild parties they enjoyed, fuelled by alcohol, occur each night. As part of this, they encourage the incidences of particularly lewd behaviour, which do occur and support the less risky but equally exotic voyeurism (Katz 1988; Urieley and Belhassen 2005; Williams-Burnett et al. 2017) providing media, post-holiday stories and free promotion. 


\section{Government Policies}

The level of permission to rebel against local regulations in the party tourism destination is significant factor. As Vanhove (1997), Cárdenas-Garcia and Sánchez-Rivero (2015) and Tsartas et al. (2014) point out tourism has great potential to contribute significantly to national and local economies. However, there is much debate and limited research as to the actual level of fiscal benefit derived from mass tourism enclaves in which the principal operators are large international companies (Monterrubio and Andriotis 2014; Williams-Burnett et al. 2017). Carlisle and Jones (2012) demonstrated how the Senegambia tourist enclave represented a powerful interplay of legislation, regulation structures and buildings that marginalized opportunities for local people to invest in tourism. Resulting from perceived limited local benefit, the national governments of many countries which are heavily reliant on tourism are seeking to move from low budget mass tourism to niche tourism. Niche tourism attracts higher spending tourists interested in the culture, nature and heritage of their destination (Park 2014) and are more likely to spend within the local economy. In the party tourism context Mintel (2016) shows that many of Spain's traditional resorts have commenced their reinvention via modernisation programmes of up- grading hotels in the quest to attract a higher-value tourism, to its shores beyond the summer months, including business tourism, arts festivals and sports training. These policies aim to increase local Spanish employment opportunities and decrease drinking on the streets via tougher laws and increased police presence.

However, while Cárdenas-Garcia and Sánchez-Rivero (2015) confirm that tourism in many forms can be a positive economic driver for many regions this does not always translate from national government policy to the local level if ignored for a (perceived) short-term gain (Tsartas et al. 2014). Nicholls (2016) points out that while technically operating under similar alcohol licencing regulations, regarding safety requirements, staff training etc. there are many variations in practice at the local level. He also notes that those countries which do not have a culture of heavy binge drinking, for example the countries bordering the Mediterranean, also tend not to have strict regulatory frameworks, making alcohol much more easily available and harder to police. This issue was exemplified by the indifference of the Mayor of, and local bar owner in, Magaluf interviewed by Stacey Dooley (BBC3 2013) who simply shrugged his shoulders and suggested he could do nothing about local party tourists and their impact upon the community. The ambivalence of the mayor reflects the findings of a limited number of studies in this area (e.g. Tutenges 2013), which suggest ambivalence amongst local business communities to party tourism. Whether in Newquay in the UK (Mawby 2012) or Kavos in Corfu, (Williams-Burnett et al. 2017) some local businesses do make a significant profit from party tourism, albeit by offering tour reps inducements to recommend their bar and or by substituting internationally branded alcohol for locally made ethanol-based alternatives.

Cárdenas-Garcia and Sánchez-Rivero (2015) also pointed out that any hosting Government, whilst recognizing the potential economic benefits all tourism including alcotourism can bring to a destination, has a responsibility to provide a safe environment for those tourists. However, Hughes et al. (2011) both highlight the large number of injuries arising from excess alcohol consumption and suggest that holidaymakers often fall into a health and safety vacuum while on holiday, neither being the long-term 
responsibility of their host country nor currently under the jurisdiction of their home country. This may result in parents and friends having to cover any medical or repatriation costs incurred (Mawby 2012). Paradoxically, Tutenges (2013) noted that the package tour operators provided their tour reps in first aid and other basic medical training and also required their tour reps to remain sober enough to be able to deal with any emergency that arose including those arising because of the excessive behaviour that they had deliberately encouraged. Kelly et al.'s (2014) study of the actual behaviour of tour reps may be considered to challenge this stated policy of care.

\section{Conclusion: Rethinking Party Enclaves}

The drawing together of extant literature has identified that there are both positive and negative aspects of alcohol consumption and party tourism for the party tourist and the community in which the party enclave is situated. This analysis has applied sociological and human geography concepts of society and communality and associated this with escapist, wild, mephitic and liminal tendencies. The authors accept the detail presented is conceptual in nature, however, it has demonstrated that there is a great deal about these interactions which is unknown and mythologised. This implies that it is not understood how positive and negative social and economic benefits to the local community and the party tourist accrue because of party tourism. Fig. 1 summarizes interactions between the local community and party tourists and identifies areas where further research is required. The authors argue that while much current research falls into the positive or negative sections of the model several themes have been identified where impact and benefit are unknown; empirical research into these themes would greatly enhance our understanding of the party tourism phenomenon and alcohol consumption.

The most important question relates to the party enclave itself. Both Fjær and Tutenges (2017) and Williams-Burnett et al. (2017) ask whether party enclaves should be discouraged. However, like prostitution or illegal drug taking, if specially designated enclaves for party tourism did not exist, it may be driven underground like the rave parties of the 1980s and 1990s in the UK (Mawby 2012) with the accompanying lack of control, increased danger to the participants and nuisance to the residents. If party enclaves are to remain, then a better understanding is needed of why UK outbound party tourists do not replicate the long-term reduction in alcohol consumption identified in the UK. The impact of social media upon both anticipated behaviour and actual behaviour also needs to be better understood, in particular the roles of pressurized rebellion and voyeurism. Any moderating behaviours identified might be used to inform policy to mitigate current social, cultural and environmental harms of party tourism.

Further economic, cultural and social research is needed to analyse a range of key topics and issues to help inform and support policy development, sustainable enclave practices and healthy drinking advice. For example, an investigation into the real fiscal benefit derived by the destination residents in the short and long term, who benefits and how, might be established using a critical analysis of bar profits during the short season of the heavy drinking party tourist. Reflecting upon the phenomenon of UK pensioners living in EU countries, the degree to which local politicians or regional authorities are 
influenced by the hidden income generated via repatriation of costs of medical or other care being claimed back from the originating country is also a key issue related to party tourism including whether the income mitigates the social and cultural impact of party enclaves upon local residents. Building on Kelly et al.'s (2014) work, which suggests large numbers of tour reps and hotel staff are young ex-party tourist themselves and return to their home country at the end of the season, analysis of levels of local and foreign employment would help to develop a better understanding of the temporal and fiscal employment impacts generated during the short party tourism season.

Additionally, analysis of types of drinking promotion, cost and benefit analysis including damage to property, impact upon the natural environment, residents and destination image needs to be further explored. This includes analysis of impacts upon local culture, social norms and cross-cultural understanding derived from hedonic and rowdy carnivalesque behaviour of party tourists and tour reps. A final theme identified which would benefit from further research is the moral and ethical responsibility of the tour operators towards both their tour reps and their customers; the extent to which tour operator and bar management strategies deliberately influence transgressive behaviours and their consequential impacts upon society at large.

Whilst this study has reviewed the party tourism phenomenon from the UK perspective, the literature available suggests that there may be similarities with young adults from other nationalities. This indicates that the need for further research is international and highlights the need for more proactive collaborative research with enclave-based organizations and public institutions. Applying sociological and human geography perspectives of embodiment of space, liminality, wild and mephitic escapism to party tourism helps to understand behaviours, motivations and impacts to reposition analysis to explore the holistic reality of party enclaves.

\section{Compliance with Ethical Standards}

\section{Conflicts of Interest) Not applicable.}

Code Availability (Software Application or Custom Code) Not applicable.

Open Access This article is licensed under a Creative Commons Attribution 4.0 International License, which permits use, sharing, adaptation, distribution and reproduction in any medium or format, as long as you give appropriate credit to the original author(s) and the source, provide a link to the Creative Commons licence, and indicate if changes were made. The images or other third party material in this article are included in the article's Creative Commons licence, unless indicated otherwise in a credit line to the material. If material is not included in the article's Creative Commons licence and your intended use is not permitted by statutory regulation or exceeds the permitted use, you will need to obtain permission directly from the copyright holder. To view a copy of this licence, visit http://creativecommons.org/licenses/by/4.0/.

\section{References}

Andrews, K. (2011). The British on holiday: Charter tourism, identity and consumption. London: Channel View Publications.

Antunes, N., Ramos, C., \& Sousa, C. (2018). Who are the tourists sharing content on social media? Behaviour and characteristics. Journal of Spatial and Organizational Dynamics, 6(3), 237-257. 
Aresi, G., \& Pedersen, E. R. (2016). 'The right level of intoxication': A grounded theory study on young adults' drinking in nightlife settings. Journal of Youth Studies, 19(2), 204-220.

Baerenholdt, J. O., Haldrup, M., Larsen, J., \& Urry, J. (2004). Performing tourist places. Aldershot: Ashgate.

BBC3 (2011 to 2015). Sun, Sex and Suspicious Parents. Accessed $11^{\text {th }}$ February 2017. https://www.youtube. com/watch? $=z 4 z 2 f F W 6 F k Q$

BBC3. (2013). Stacey Dooley Investigates; the truth about Magaluf Season 1-episode 3 January. Accessed $11^{\text {th }}$ February 2017 http://www.bbc.co.uk/programmes/b01bclzxruary

Bell, D. (2008). Destination drinking: Towards a research agenda on alcotourism. Drugs: Education, Prevention and policy, 15(3), 291-304.

Bellis, M. A., Hughes, K., Jones, L., Morieo, M. Nicholls, J. McCoy, E., Webster, J. \& Sumnall, H. (2015) Holidays, celebrations, and commiserations: Measuring drinking during feasting and fasting to improve national and individual estimates of alcohol consumption. BMC Medicine. 13 (113) open access. https://doi.org/10.1186/s12916-015-0337-0.

Best, P., Manktelow, R., Taylor, B. (2014). Online communication, social media and adolescent wellbeing: A systematic narrative review. Children and Youth Services Review, 41, 27-36.

Bosangit, C., Hibbert, S., \& McCabe, S. (2015). "If I was going to die I should at least be having fun": Travel blogs, meaning and tourist experience. Annuals of Tourism Research, 55, 1-14.

Braun, V., \& Clarke, V. (2006). Using thematic analysis in psychology. Qualitative Research in Psychology, $3(2), 77-101$.

Briggs, D. (2012). Deviance and risk on holiday: an ethonography with British youth abroad. In S. Winslow \& R. Atkinson (Eds) New directions in crime and deviance. (pp127-144) London: Routledge.

Briggs, D. (2013). Deviance and risk on holiday: An ethnography of British tourists in Ibiza. London: Springer.

Burton, R., Henn, C., Lavoie, D., O’Connor, R., Perkins, C., Sweeney, K., Greaves, F., Ferguson, B., Benyon, C., Belloni, A., Musto, V., Marsden, J., Sheron, N., \& Wolff, A. (2016). The public health Burdon of alcohol and the effectiveness and cost-effectiveness of alcohol control policies; a evidence review. London: Public Health England.

Cable, N., \& Sacker, A. (2007). The role of adolescent social dis-inhibition expectancies in moderating the relationship between psychological distress and alcohol use and misuse. Addictive Behaviours, 32, 282295.

Cárdenas-Garcia, P. J., \& Sánchez-Rivero, M. (2015). Tourism and economic development: An analysis of geographic features and infrastructure provision. Current Issues in Tourism, 18(7), 609-632.

Carlisle, S., \& Jones, E. (2012). The beach enclave: A landscape of power. Tourism Management Perspectives, 1, 9-16.

Carlisle, S., Kunc, M., \& Johansen, A. (2016). Strategic foresight for (coastal) urban tourism market complexity: The case of Bournemouth. Tourism Management, 54, 81-95.

Carr, N. (2002). Going with the flow: An assessment of the relationship between young people's leisure and holiday behaviour. Tourism Geographies, 4(2), 115-134.

Chaney, D. (1993). Fictions of Collective Life. London: Routledge.

Cogan, L., \& Charters, S. (2014). Wine tourism. In S. Charters \& J. Gallo (Eds.), Wine Business Management (pp. 221-234). Paris: Pearson.

Craik, J. (1997). The Culture of Tourism. In Rojek, C. and Urry, J. (Eds.) Touring Cultures: Transformation of Travel and Theory. (pp.113-136). New York: Routledge.

Croft, J. (2017). Youth Culture and Style. In M. Storry \& P. Childs (eds.) British Cultural Identities (5th ed.) (pp. 153-182). London: Routledge.

Crouch, D., Arransson, L., \& Wahlstrom, L. (2001). Tourist encounters. Tourist Studies, 1(3), 253-270.

Edensor, T. (2001). Performing tourism, staging tourism: (re)producing tourist space and practice. Tourist Studies, 1(1), 59-81.

Eliade, M. (1968). Myth and Reality. Madrid: Guadarrama

Euromonitor. (2016). Alcoholic Drinks in the United Kingdom - June. Accessed 20th January 2017. http://www.portal.euromonitor.com.ezproxy.cardiffmet.ac.uk/portal/analysis/related

Fennel, D. (2006). Tourism ethics. London: Channel View.

Fereday, J., \& Muir-Cochrane, E. (2006). Demonstrating rigor using thematic analysis: A hybrid approach of inductive and deductive coding and theme development. International Journal of Qualitative Methods, $5(1), 80-92$.

Ferraz Ribeiro, J., \& Moreira, G. (2015). (O)Porto: A wine, a place, a route and a meeting point. In A. D. Barker (Ed.), Identity and intercultural exchange in travel and tourism (pp. 171-188). Bristol: Channel View Publications.

Fink, C. (1970). Mass Tourism. Berne: Paul Haupt 
Fishbein, M., \& Ajzen, I. (1975). Belief, attitude, intention, and behavior: An introduction to theory and research. Reading: Addison-Wesley.

Fjær, E. G., \& Tutenges, S. (2017). Departies: Conceptualizing extended youth parties. Journal of Youth Studies, 20(2), 200-215.

Fox, K. (2004). Watching the English: The hidden rules of English behaviour. London: Hodder.

Giddens, A. (1987). Social Theory and Modern Sociology. Cambridge: Polity Press.

Gunter, B., Hansen, A. \& Touri, M. (2008) The reception and representation of meaning in alcohol advertising and Young People's drinking. Alcohol Research UK. February. Alcohol Insight 55.

Hall, C. M., Sharples, L., Cambourne, B., \& Macionis, N. (Eds.). (2000). Wine tourism around the world; development, management and markets. Oxford: Butterworth Heinemann.

Hastings, G. (2010) "They'll drink bucket loads of the stuff'. An Analysis of internal alcohol industry advertising documents. Alcohol Research UK - April. Alcohol Insight, 71.

Hesse, M., Tutenges. S., Schliewe, S. \& Reinholt, T. (2008) Party package travel: Alcohol use and related problems in a holiday resort: A mixed methods study. BMC Medicine. 8 (351).

Holmes, J., Lovatt M., Ally, A., Brennan A. \& Meier, P. (2016) New approaches to measuring drinking cultures in Britain. Alcohol Research UK April Alcohol Insight 133.

Hughes, K., Bellis, M., Calafat, A., Blay, N., Kokkevi, A., Boyiadji, G., Do Rosario Mendes, R., \& Bajcarova, L. (2011). Substance use, violence and unintentional injury in Young holidaymakers visiting Mediterranean destinations. Journal of Travel Medicine, 18(2), 80-89.

Katz, J. (1988). Seductions of crime: Moral and sensual attractions in doing evil. New York: Basic Books.

Kelly, D., Hughes, K., \& Bellis, M. (2014). Work hard, party harder: Drug use and sexual behaviour in Young British casual Workers in Ibiza, Spain. International Journal of Environmental Research and Public Health, 11, 10051-10061.

Larsen, J. (2012). Performance space and tourism. In J. Wilson (Ed.), The Routledge handbook of tourism geographies (pp. 67-73). London: Routledge.

Lefebvre, H. (1991). Production of Space. Oxford: Blackwell.

Lew, A. L., \& Cartier, C. (2004). Seductions of place. Geographical Perspectives on Globalization and Touristed Landscapes. London: Taylor and Francis.

Lim, W. M. (2014). The antecedents and consequences of customer hedonism in hospitality services. Journal of Hospitality Marketing and Management, 23, 626-651.

Lobstein, T., Landon, J., Thornton, N., \& Jernigan, D. (2016). The commercial use of digital media to market alcohol products: A narrative review. Addiction, 112(1), 21-27.

Lyng, S. (1990). Edgework: A social psychological analysis of voluntary risk taking. American Journal of Sociology, 95(4).

Lyng, S. (2005). Edgework: The sociology of risk taking. Abingdon: Routledge.

Mawby, R. (2012). Public disorder, antisocial behaviours and alcohol-related crime: From the metropolis to the tourist resort. In C. Jones, E. Barclay, \& R. Mawby (Eds.), The Problem of Pleasure: leisure, tourism and crime (pp. 93-107). London: Routledge.

Mintel. (2016). Travel and Tourism - Spain - August 2016. Mintel Reports. Mintel Publishing

Monterrubio, J. C., \& Andriotis, K. (2014). Social representation and community attitudes towards spring breakers. Tourism Geographies, 16(2), 288-302.

Moore, K., \& Measham, F. (2012). Impermissible pleasures in the UK: Exploring policy developments in alcohol and illicit drugs. In C. Jones, E. Barclay, \& R. Mawby (Eds.), The problem of pleasure: Leisure, tourism and crime (pp. 62-76). London: Routledge.

Nicholls, J. (2016). Alcohol policy in global context. In T. Kolind, B. Thom, \& G. Hunt (Eds.), The sage handbook of drug and alcohol studies: Social science approaches (pp. 164-180). Sage Publications Ltd: London.

Niland, P., Lyons, A., Goodwin, I., \& Hutton. (2014). 'See it doesn't look pretty does it?' Young adults airbrushed drinking practices on Facebook. Psychology \& Health, 29(8), 877-895.

On the Beach. (2017). accessed 11th February 2017 https://www.onthebeach.co.uk/holidays/lifestyleholidays/clubbing-holidays?mv_pc=googlecpc\&CampaignID=211389743\&AdGroupID=14671329743 $\&$ Keyword=aud-229885504343:kwd-6536925990\&MatchType=e \&Device=c \&AdID=168106156241 \&gclid=Cj0KEQiAifvEBRCVx5up6Ojgr5oBEiQALHw1TqTr4NEzEQ66d-Q1 AvJo-z960FFQZidKGvA6ObN0mIaAun78P8HAQ

ONS. (2015). Opinions and Lifestyle Survey, Adult Drinking Habits in Great Britain, 2013. Office for National Statistics. Accessed 20 ${ }^{\text {th }}$ January $2017 \mathrm{http}: / /$ webarchive.nationalarchives.gov. uk/20160105160709/http://www.ons.gov.uk/ons/rel/ghs/opinions-and-lifestyle-survey/adult-drinkinghabits-in-great-britain\%2D\%2D2013/index.html

Park, H.-y. (2014). Heritage tourism. London: Routledge. 
Piggot, M. (2016). Spain: British tourist dies after falling from $3^{\text {rd }}$ floor balcony in Magaluf. International Business Times; accessed $7^{\text {th }}$ November 2016. http://www.ibtimrs.co.uk/spain-british-tourist-dies-afterfalling-3rd-floor-balcony-magaluf- 1579020

Pikkemaat, B., Peters, B., Boksberger, P., \& Secco, M. (2009). The staging of experiences in wine tourism. Journal of Hospitality Marketing and Management, 18, 237-253.

Pine, B. J., \& Gilmore, J. H. (2011). The experience economy. Boston: Harvard Business Review.

Pritchard, A., \& Morgan, N. J. (1996). Sex still sells to generation X: Promotional practice and the youth package holiday maker. Journal of Vacation Marketing, 3(1), 69-80.

Purves, R., Stead, M. \& Eadie, D. (2014). "What are you meant to do when you see it everywhere?" Young people, alcohol packaging and digital media. Alcohol Research UK, December. Alcohol Insight 120.

Ragsdale, K., Difranceisco, W., \& Pinkerton, S. D. (2006). Where the boys are: Sexual expectations and behaviour amongst young women on holiday. Culture, Health \& Sexuality, 8(2), 85-98.

Redmon, D. (2003). Playful deviance as an urban leisure activity: Secret selves, self-validation and entertaining performances. Deviant Behaviour: An Interdisciplinary Journal, 24, $27-51$.

Ritchie, C., Ritchie, F., \& Ward, R. (2009). A good night out; alcohol related behaviours in young adults. Worldwide Hospitality and Tourism Themes, 1(2), 169-193.

Rojek, C. (2000). Leisure and culture. Basingstoke: Palgrave Macmillan.

Rojek, C. (2005). Leisure theory. Basingstoke: Palgrave Macmillan.

Room, R. (2005). Multi-cultural contexts and alcohol and drug use as symbolic behaviour. Addiction Research and Theory, 13(4), 321-331.

Ryan, T., Allen, K. A., Gray, D. L., \& McInerney, D. M. (2017). How social are social media? A review of online social behaviour and connectedness. Journal of Relationships Research, 8, 1-8.

Smith, L. A. \& Foxcroft, D. R. (2007). The Effect of Alcohol Advertising and Marketing on Drinking Behaviour in Young People: a Systematic Review of Published Longitudinal Studies. Alcohol Research UK. November. Alcohol Insight 51.

Snowdon, C. (2015). Drinking fast and slow; ten years of the Licencing act. Institute for Economic Affairs. May Publication.

Storry, M., \& Childs, P. (2017). British cultural identities (5th ed.). London: Routledge.

Thomas, M. (2005). What Happens in Tenerife Stays in Tenerife: Understanding Women's sexual Behaviour on Holiday. Culture, Health and Sexuality, 7(6), 571-584.

Thompson. (2017). Clubbing Holidays Reinvented. Accessed 11 th February 2017 http://www.thomson.co. uk/holidays/scene?im_id=PPC\&s_kwcid=39700014245541011\&gclid=Cj0KEQiAifvEBRCVx5up6 Ojgr5oBEiQALHw1Tohyna6E4RzICPogZSvF-Z1PWEGwecMm8dWPWqm2DZIaAh2X8P8 HAQ\&gclsrc=aw.ds

Thurnell-Read, T. (2011). Off the leash and out of control: Masculinities and embodiment in eastern European stag tourism. Sociology, 45(6), 977-991.

Thurnell-Read, T. (2012). What happens on tour: The premarital stag tour, Homosocial bonding and male friendships. Men and Masculinities, 15(3), 249-270.

Tsartas, P., Papatheodorou, A., \& Vasileiou, M. (2014). Tourism development and policy in Greece. In C. Costa, E. Panyik, \& D. Buhalis (Eds.), European tourism planning and organisation systems; the EU member states (pp. 295-306). Bristol: Channel View Publications.

Turi, K. (2017) What Happens in Sunny Beach, Season 1 Episode 1. Accessed 20 th January 2017 https://www. youtube.com/watch?v=W7zvPg3cTok

Tutenges, S. (2012). Nightlife tourism: A mixed methods study of young tourists at an international nightlife resort. Tourist Studies, 12(2), 131-150.

Tutenges, S. (2013). Stirring up effervescence: An ethnographic study of youth at a nightlife resort. Leisure Studies, 32(3), 233-248.

Tutenges, S. \& Sanberg, S. (2013). Intoxicating Stories: the characteristics, contexts and implications of drinking stories among Danish youth. International Journal of Drug Policy, 24(6), 538-544.

UNWTO. (2016 Edition). Tourism Highlights. United Nations World Tourism Organisation (UNWTO) Publication.

Uriely, N., \& Belhassen, Y. (2005). Drugs and risk-taking in tourism. Annuals of Tourism, 33(2), 339-359.

Vanhove, N. (1997). Mass tourism: Benefits and costs. In S. Wahab \& J. J. Pigram (Eds.), Tourism, development and growth: The challenge of sustainability (pp. 50-77). London: Routledge.

Velikova, N., Charters, S., Fountain, J., Ritchie, C., Dodd, T., Thach, E., \& Fish, N. (2016). Status or fun? A cross-cultural examination of younger consumers' responses to images of champagne and sparkling wine. British Food Journal, 118(8), 1960-1975.

Wang, N. (1999). Rethinking authenticity in tourism experience. Annals of Tourism Research, 26(2), 349370 . 
Wearing, S., Stevenson, D., \& Young, T. (2010). Tourist cultures: Identity, place and the traveller. London: Sage.

Williams-Burnett, N., Skinner, H., \& Fallon, J. (2017). What REALLY happens in Kavos. Journal of Place Management, 10(2), 183-195.

Wilson, J. (Ed.). (2012). The Routledge handbook of tourism geographies. London: Routledge.

Publisher's Note Springer Nature remains neutral with regard to jurisdictional claims in published maps and institutional affiliations. 